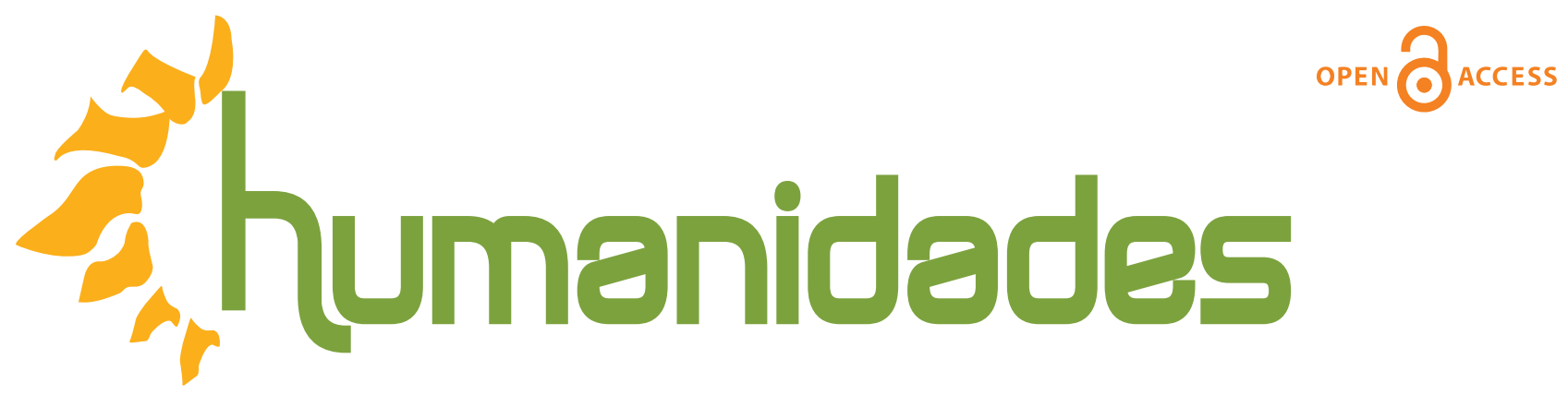

Revista de la Escuela de Estudios Generales, Universidad de Costa Rica

Julio-diciembre, 2019 •Volumen 9, número 2 • EISSN 2215-3934 • pp. 1-25

Recibido: 28-Febrero-2019 Aceptado: 17-Abril-2019

\title{
La materialidad e inmaterialidad en el arte digital: conceptos clave para comprender su inmanencia
}

DOI: https://doi.org/10.15517/h.v9i2.37706

\section{Claudia Mosqueda Gómez}

Doctora

Universidad Autónoma Metropolitana, Unidad Lerma, México

Correo electrónico: c.mosqueda@correo.ler.uam.mx / claudiamosg@yahoo.com.mx

Todos los derechos reservados. Universidad de Costa Rica. Esta revista se encuentra licencida con Creative Commons. Reconocimiento-NoComercial-SinObraDerivada 3.0 Costa Rica. Correo electrónico: humanidades@ucr.ac.cr/ Sitio web: http: //revistas.ucr.ac.cr/index.php/humanidades 


\title{
La materialidad e inmaterialidad en el arte digital: conceptos clave para comprender su inmanencia
}

\section{Resumen}

Este artículo pretende demostrar la manera en la que la obra de arte digital posee cualidades inmanentes entre lo material y lo inmaterial, operando sobre expresiones artísticas como conceptos unívocos. Lo material, tangible, registro fehaciente de cambios y transformaciones de lo concreto; lo inmaterial: modo de asumir lo intangible de la obra: conductas, percepciones y formas de existencia que operan en el mundo de lo artístico como potencia de objetividad sin que pueda aún tener un sustrato material. Ambas formas de existencia se presentan en los objetos y productos del arte digital e interactivo a través de la inmanencia.

\section{Materiality and Immateriality in Digital Art: Key Concepts for Understanding its Immanence}

\begin{abstract}
This article aims to demonstrate the way in which the digital work of art possesses immanent qualities between the material and the immaterial, operating on artistic expressions as univocal concepts. The material, tangible, reliable record of changes and transformations of the concrete; the immaterial: way of assuming the intangible of the work: behaviors, perceptions and forms of existence that operate in the world of the artistic as a power of objectivity without it still having a material substrate. Both forms of existence are presented in the objects and products of digital and interactive art through immanence.
\end{abstract}

Palabras clave: cultura contemporánea, arte digital, ciber arte, interacción

Keywords:

contemporary culture, digital art, cyber art, interaction 
La materialidad e inmaterialidad en el arte digital...

Hay que estar presente, en el presente de la imagen, en el minuto de la imagen: si hay una filosofía de la poesía, ésta (sic) filosofia debe nacer y renacer con el motivo de un verso dominante, en la adhesión total a una imagen aislada, y precisamente en el éxtasis mismo de la novedad de la imagen...

G. Bachelard

\section{Introducción}

Las expresiones virtuales e interactivas que singularizan la producción de la obra de arte son conceptos unívocos. En este sentido, la obra de arte digital posee cualidades inmanentes entre lo material e inmaterial, dichos elementos, en las obras de arte digital operan como atributos que forman un absoluto, es decir, no se escinden, son impensables de manera fragmentada y responden a la univocidad del arte. Lo material refiere a los sustratos tangibles o infraestructurales de la obra y lo inmaterial se refiere a los procesos perceptuales, sensibles o empíricos.

Se parte de la premisa de que dentro de los discursos del arte electrónico o digital se produce una escisión entre la materialidad de los dispositivos y la inmaterialidad de las experiencias simuladas como formas artificiales de realidad desplegando modos virtuales de experiencia estética que solo representan escenas ficticias o irreales. Ahora bien, a las obras de arte con soportes virtuales se les suele llamar obras de ilusión o inmersión, irreales o inexistentes pero esto no es así, ya que la virtualidad es una forma de realidad tangible e intangible. Es decir, la potencialidad de la obra no radica en la existencia perenne de su sustrato material, sino que su belleza también está en potenciar sensibilidades y emociones a partir de la inmaterialidad de los ambientes virtuales inmersivos.

Por supuesto, no debe negarse el carácter inmanente de lo material y lo inmaterial en este tipo de manifestación artística, en este sentido concreto, puede afirmarse que no hay una fragmentación entre estas categorías, o que una es superior frente a la otra. Este artículo se propone entender lo material y lo inmaterial, desde la perspectiva filosófica, como univocidad desde el pensamiento de Gilles Deleuze (1996). 
En lo que respecta a la estructura metodológica de este trabajo se desarrolla de la siguiente forma: en primer lugar, se abarca el contexto tecnológico de la época en que se desarrolla la obra de arte digital; en segundo lugar, se abarca el momento en el que se trabajan los esquemas de pensamiento desde la perspectiva filosófica de Deleuze que permitan entender lo virtual, concepto que explicaría la univocidad de la inmanencia; en tercer lugar, se buscan comprender estos conceptos a partir de lenguajes de obras de arte digital que despliegan mundos virtuales interactivos: Osmoses obras de Char Davies (1995); finalmente, se ofrecen algunas ideas a modo de reflexiones finales.

\section{Ideas generales de la época}

Los avances científicos y tecnológicos de las últimas décadas del fin del siglo XX direccionaron un mundo plagado de múltiples imágenes. La vertiginosa evolución de la tecnología propició un cambio radical en los modos de pensar y producir. De esta manera, se rompió la secuencia lineal de los procesos y estrategias de producción que imperaban hasta antes de los sesenta, iniciándose así, la transición de lo lineal a lo digital (complejo). En las postrimerías de siglo se ha reconfigurado la preponderancia del lenguaje visual tecnologizado. La esencia virtual que se desata de este imaginario artístico se despliega en espacios físico-materiales e inmateriales.

Ahora bien, la primera dimensión del espacio social a desarrollar se concibe como las circunstancias que influyen en la producción de estas obras. En otras palabras, se trataría de explicar Los espacios de flujo de Manuel Castells (1996), como referente teórico para definir cómo se han reconfigurado las interacciones sociales en la "sociedad de la información" de finales del siglo XX y principios del XXI, como contexto que prefigura la producción de la obra de arte. La segunda dimensión, se refiere al espacio del que se sirven en la obra para conceptualizar y dar sentido compositivo. Además, la noción de Ciberespacio que aporta Lévy (2007) contribuye a definir el modo en que las artes digitales se han apropiado de la idea de ciberespacio para fundamentar la composición virtual e interactiva de las obras y lenguajes artísticos. 
La materialidad e inmaterialidad en el arte digital...

Entonces, se presentan primero las definiciones de Los espacios de flujo propuesto por Manuel Castells, orientando su exégesis a la producción de los artes digitales. Luego, se continúa por otra parte con las distinciones de los fundamentos del ciberespacio: virtual e interactividad, que sustentan la producción de la obra arte digital.

\section{Espacio de flujos}

Es importante partir de la premisa de que el arte no está escindido de los procesos sociales, es incluso, un proceso social porque forma parte de la estructura que permite la producción, circulación y consumo de obras de arte en determinados espacios o contextos históricos específicos. Dado que las creaciones objetivas del espíritu nunca deben ser opuestas al acontecimiento social, y solo pueden ser consideradas en una correlación funcional con él en los campos de acción de la cultura, todo sociólogo animado de pensamiento moderno reconoce actualmente que las artes, así como la economía, el derecho, la religión, el Estado, etcétera, son, en definitiva, la resultante de interconexiones culturales y sociales, lo que estaría demostrado por la diversidad de ángulos bajo los cuales pueden considerarse esos fenómenos: expresiones simbólicas, procesos de comunicación y, en última instancia, procesos sociales (Silbermann, 1971, p. 16).

Además, ya que el arte se relaciona con su contexto social, puede suponerse que compartan las concepciones sociohistóricas específicas. La noción de espacio social que se tenga en un determinado contexto sociohistórico, no se escinde de la producción artística porque ya forma parte de ella al definir procesos con los que habrá de irrumpirse y establecer relaciones sociales complejas. Se trata de un proceso dado que, al mismo tiempo se va actualizando en un continuum permanente. Según lo anterior, cuando cambia la perspectiva del espacio social en la sociedad, esta permea y transforma también al arte, alterando, modificando, incidiendo y atravesando todos los procesos de su configuración, distribución y circulación. Siguiendo a Lefebvre (1974): "El concepto de la producción del espacio está naciendo como la realidad en sí a la que le corresponde. Esta producción del espacio está naciendo en sí misma" (Lefebvre, 1974, pp. 219-220). El sentido de espacio 
social afecta o modifica en su configuración de acuerdo a las condiciones en que se transforma y construye la realidad. El espacio de flujos al que se refiere Castells tiene sentido como forma de realidad porque su soporte está en la sociedad red, como el esquema social plurimórfico a partir del cual se reordenan los procesos tecnológicos.

Siguiendo a Lefevbre (1974), si el espacio social responde a procesos dominantes de los modelos económicos, significa que este concepto al que asiste la producción de las artes digitales es al proyecto de la globalización, por lo que la noción dominante de espacio social en la Globalización es el espacio de flujos definido por Castells (1996). Este autor afirma que el espacio de flujos es verdaderamente la forma dominante de la sociedad red. La dinámica de esta sociedad emerge de los flujos informáticos, tecnológicos, económicos, visuales, sonoros u organizativos que circulan en redes complejas de información permitiendo la invasión simultánea y efímera de los individuos. Esta dinámica del espacio social adquiere nuevas cualidades porque en gran parte está dada por los procesos tecnológicos e informáticos. Es importante mencionar entonces que las cualidades de dicho espacio están unívocamente entre lo material e inmaterial.

En el Espacio de flujos, la llegada se vuelve elusiva, virtualmente indistinguible de la salida. Castells (1996) escribe: "Nuestras sociedades están construidas alrededor del concepto de "flujo": flujo de capital, flujo de información, flujo de tecnología, flujo de interacciones organizacionales, flujo de imágenes, sonidos y símbolos. El flujo no es sólo un elemento de la organización social es la expresión de los procesos dominando nuestra vida económica, política y simbólica" (Castells citado por San Cornelio y Alsina, 2010, pp. 110-111).

Si bien para este pensador el espacio es la expresión de la sociedad, la sociedad red tendría su manifestación máxima en los espacios de flujo, configurados por la compleja interconexión de nuevos modos de establecer relaciones sociales, pues en el espacio se reúnen simultáneamente muchos otros espacios sociales. 
La materialidad e inmaterialidad en el arte digital...

"El espacio es el soporte material de las prácticas que comparten el tiempo [...] por lo tanto propongo la idea de que hay una nueva forma espacial característica de las prácticas sociales que dominan y conforman la sociedad red: el espacio de flujos" (Castells, 1996, p. 445).

El espacio de flujos se caracteriza por sostenerse de tres capas de soportes material: 1) la primera capa es toda la infraestructura tecnológica que soporta la afluencia de información; 2) la segunda capa está sostenida por los nodos y ejes. En este sentido, los nodos conectan funciones organizadas jerárquicamente en la sociedad red según su grado de importancia. Por su parte, los ejes, son intercambiadores de comunicación para que haya interacción uniforme de todos los elementos integrados en la red; 3) la tercera capa es la organización espacial de las élites gestoras dominantes. Castells (1996) dice que la sociedad red está configurada asimétricamente dados los intereses de las élites dominantes de la estructura social (p. 449).

El espacio de flujos está sostenido por una serie de soportes materiales que territorializan, desterritorializan o reterritorializan las interconexiones de informaciones, de prácticas, conductas o sujetos. Tiene sentido que Castells (1996) diga que los espacios de flujo no impregnan toda la experiencia humana de la sociedad red, porque aún persiste el arraigo y la territorialización de prácticas sociales dadas por la propia espacialidad del terruño. Los espacios de flujos son también flujos virtuales inmateriales. De esta forma, se trata de lugares sin referente físico por los cuales circulan y se mueven millones de datos, sonidos, imágenes, informaciones o sujetos que configuran, resignifican, segmentan, yuxtaponen o diseminan las nuevas formas de socialización y producción cultural en la sociedad red. En este caso, el arte no estaría exento de ser redefinido por el espacio de flujos de la sociedad red. En este sentido el espacio de flujos es el soporte inmaterial de las prácticas de los artes digitales. Estas obras artísticas están circunscritas y son atravesadas por los procesos tecnológicos dominantes de la sociedad red. 
Entonces, la obra de arte se vuelve compleja, polisémica, multicéntrica, simultánea y referencial al incorporar los procesos creadores con las tecnologías de la información, con plataformas virtuales, con sofisticados artefactos que lean, reproduzcan, simulen estímulos perceptuales humanos, soportes que propicien la interacción con los espectadores, y es que las relaciones sociales presenciales y físicas, las conductas o prácticas sociales se vuelven una red fluida de intercambios, de conductas, lenguajes, socializaciones, en fin, nuevas formas de vivir, pensar, de actuar organizadas por un nuevo espacio social: El espacio de flujos.

\subsection{Ciberespacio}

El ciberespacio es un concepto que surgió en la literatura y que reflejó la gestación de la cultura digital en la década de los ochenta. A diferencia de la definición sociológica del espacio de flujos, el ciberespacio es un concepto literario y filosófico que se origina en la obra literaria Neuromante de William Gibson (1984). En esta perspectiva literaria el Ciberespacio es:

Una alucinación consensuada experimentada diariamente por miles de millones de operadores legítimos en todas las naciones, por ejemplo, niños a quienes les enseñan conceptos matemáticos... Una representación gráfica de datos sacados de las bases de todos los ordenadores del sistema humano. Una complejidad impensable. Líneas de luz ordenadas en el no-espacio de la mente, agrupaciones y constelaciones de datos. Como las luces de una ciudad que se alejan. (Gibson, 2001, p. 132)

Ya Gibson (2001) advierte que sus ideas establecen una relación del hombre con el cosmos, pero no como imaginación burda del mundo cósmico sino de un concepto visionario en donde el tiempo y el espacio no tienen principio y fin. El ciberespacio es un espacio producto de alucinaciones dentro de un espacio real e intangible, en él el hombre habita, entra y sale cuando quiere, es un espacio desterritorializado en el que se puede viajar, pernoctar de modo efímero dentro de un torrente de luz casi ilegible, inasible y sin embargo espacio vivible. Las ideas de Gibson expresadas en Neuromante son, quizá, la influencia más significativa para describir el mundo simulado del que se sustraen los imaginarios de la cibercultura. 
La materialidad e inmaterialidad en el arte digital...

De esta manera particular, esta visión literaria de finales de los años ochenta aportó perspectivas e imaginarios para mirar la emergencia de las tecnologías de la nueva infraestructura de la cultura de la comunicación y expresiones teologizadas. Dice Pierre Lévy (2007) al respecto: "Las tecnologías del lenguaje digital aparecieron como infraestructura del ciberespacio, nuevo espacio de comunicación, de sociabilidad, de organización y transformación, pero también nuevo mercado de la información y conocimiento" (p. 18).

El ciberespacio está formado por una multiplicidad de líneas en las que se desplaza la información, transacciones y relaciones complejas desterritorializadas, el ciberespacio se extiende como redes de relaciones que están en todos lados y en ninguna parte. El ciberespacio es un mundo al que todos pueden tener acceso. $\mathrm{Su}$ vida fluye atemporalmente dentro del territorio o dentro de los espacios físicos con sus referentes materiales que pierden sentido para ubicar a la virtualidad como la esencia del ciberespacio. No hay cuerpos presentes, hay sólo presencias virtuales, identidades efímeras, mentes, sensibilidades y emociones que fluyen y se reconectan cada vez que la narcosis de la alucinación les permite vivir dentro de las vorágines de un espacio construido por miles de millones de intersubjetividades.

El ciberespacio refiere a la inmaterialidad que sólo tiene sentido en la construcción de una realidad virtual. Lévy (2007) define al ciberespacio como:

El espacio de comunicaciones abierto por la interconexión mundial de los ordenadores y de las memorias informáticas. Esta definición incluye el conjunto de sistemas de comunicación electrónicos en la medida que se transportan informaciones provenientes de fuentes digitales o destinadas a la digitalización. Insisto sobre la codificación digital pues condiciona el carácter plástico, fluido, finamente calculable y tratable en tiempo real, hipertextual, interactivo y para decirlo todo, virtual, de la información que es, me parece la marca distintiva del ciberespacio. (pp. 70-71)

En el ciberespacio, el espacio físico y el tiempo cronológico se transfiguran, mutan, se reconstituyen ofreciendo nuevas posibilidades en las que circula la información a una velocidad vertiginosa y difícil de asir. 
Ahora se habla de un espacio de encuentro virtual y de interacción que desdibuja los espacios físicos para posibilitar la mutualidad inmaterial entre los sujetos y las interfaces, artefactos u ordenadores. Este espacio social, físico o informacional, incluso artístico, se desterritorializa, vuelve anónimo al autor y al espectador.

Siguiendo a Lévy, máximo teórico de la cibercultura, se puede definir que el ciberespacio tiene dos tendencias fundamentales: la virtualidad y la interacción. De tal modo que la producción de cualquier objeto de la cibercultura tiene cualidades o rasgos virtualizantes y virtualizadores, tanto los procesos de interacción social e individual como los procesos creadores de las obras de arte que producen otras formas de realidad. Mientras que en la interacción en el ciberespacio se refleja como una conducta altamente activa en la que el espectador despliega toda forma de experiencia humana.

\section{Esquemas de pensamiento sobre lo virtual}

Antes se dijo que la materialidad e inmaterialidad son cosas no separadas o escindidas, por el contrario, mantienen una inmanencia. Tal relación no es una simple pareja de cosas o conceptos. La inmanencia, como la piensa Deleuze (1996), tiene una clara influencia de Spinoza. En este sentido, desde el pensamiento de Spinoza la inmanencia se comprende como sigue:

Dios es causa inmanente, pero no transitiva de todas las cosas. El modo como Spinoza hace uso de la noción de inmanencia indica que se trata no sólo de distinguir entre dos modos de acción, sino también de hacer de uno de estos modos el verdaderamente "real", por ser a la vez el plenamente "racional"1 (Ferrater, 1965, p. 961)

La noción de inmanencia de Spinoza no distingue a lo uno y lo otro como dos formas, dos continentes o dos acciones. En concreto, son una sola acción. Lo uno contiene a lo otro y lo otro a lo uno. En palabras más cercanas a Spinoza, Dios está en todas las cosas que ha creado y todas las cosas que ha creado son Dios. 
La materialidad e inmaterialidad en el arte digital...

Para Spinoza, el Todo y todos los existentes son cosas integradas en una sola unidad que contiene a uno y otro, sin separar, sin disociar, porque se trata de una integración.

La inmanencia Spinoziana² fundamenta las ideas de Deleuze y Guattari (1993) cuando ambos autores se refieren a la virtualidad como la inmanencia de lo uno y lo múltiple. En la virtualidad el Ser no está escindido, no es trascendental sino inmanente. Se trata de pensar la virtualidad como un ser inmanente. Específicamente, para Deleuze (1996), el Ser (hombre) es un proceso, un flujo, acontecimiento, vida, intensidad, un sujeto que se mueve como un nómada en su propia vida, un despliegue infinito de su ser, pero estos movimientos se revelan de modo inmanente.

La participación encuentra su principio, ya no en una emanación de la que el Uno sería la fuente más o menos próxima, sino que en la expresión inmediata y adecuada de un Ser absoluto que comprende todos los seres y se explica por la esencia de cada uno. La expresión comprende todos estos aspectos: complicación, explicación, inherencia, implicación. Estos aspectos de la expresión son también las categorías de la inmanencia; la inmanencia se revela expresiva, la expresión inmanente en un sistema de relaciones lógicas en el que ambas son correlativas (Deleuze, 1996, p. 171)

De tal manera que la inmanencia que Deleuze lee de Spinoza tiene sentido en su correlato en la univocidad; Uno-Todo, Omnitodo, los incluye a todos en un único y mismo plano. Desde este razonamiento es posible pensar que el arte con ambientes virtuales asiste a una relación univoca entre lo material e inmaterial. Ya no existe obra o experiencia artística que no sea solo material o inmaterial porque el contexto del que procede la práctica es cada vez más dinámica y vertiginosa. En el contexto de la sociedad digital, los sujetos se vuelven a los sujetos más activos y reactivos a sus condiciones socioculturales, el sujeto que habita en la Sociedad Global acaba por construirse en el anonimato de los no-lugares, espacios sin identidad no solo físicos, sino virtuales. 
Hemos opuesto lo virtual a lo real; hasta ahora es preciso corregir esa terminología, que todavía no podía ser exacta. Lo virtual no se opone a lo real, sino tan solo a lo actual. Lo virtual posee una realidad plena en tanto virtual. De lo virtual es preciso, exactamente, lo que Proust decía de los estados de resonancia: $<<$ Reales sin ser actuales, ideales sin ser abstractos $>>$, y simbólicos; sin ser ficticios. Lo virtual hasta debe ser definido como una estricta parte del objeto real, como si el objeto tuviera una de sus partes en lo virtual, y se sumergiera allí como en una dimensión objetiva (Deleuze, 2002, p. 314)

En este orden de ideas, lo virtual no se antepone a lo real porque es otra forma de construcción de la realidad que se hace posible porque el ciberespacio es su medio, el espacio desterritorializado en que fluyen miles y millones de construcciones que edifican un nuevo espacio y una nueva realidad. Entonces, lo virtual en tanto forma de realidad desata nuevas formas de interacción social nunca antes pensadas o conocidas, crea sujetos nómadas que circulan por las rutas efímeras y rizomáticas de la virtualidad. Además, la inmaterialidad de lo virtual tiene su soporte material en los procesos digitalizados de las nuevas tecnologías, desde ahí, se hace posible el establecimiento de la interacción del sujeto-objeto que se detona en esta realidad alternativa porque se alteran, distorsionan y crean otras formas de percibir las realidades alternativas. La virtualidad es una imagen o espacio que no es real pero lo parece.

Asimismo, lo virtual es una construcción de realidad que no tiene ubicuidad territorial porque es producto de un espacio desdibujado físicamente. Es un nuevo tipo de realidad que esboza mundos virtuales en los que se puede vivir, en donde se despliegan todo tipo de experiencias potenciales que se hacen virtuales.

Hemos visto que un doble proceso de determinación recíproca y de determinación completa definía esa realidad: lejos de ser indeterminado, lo virtual está completamente determinado. Cuando la obra de arte invoca una virtualidad en la que se sumerge, no invoca ninguna determinación confusa, sino la estructura completamente determinada que forman sus elementos diferenciales genéticos, elementos virtualizados, embrionizados. 
La materialidad e inmaterialidad en el arte digital...

Los elementos, las variedades de relaciones, los puntos singulares, coexisten en la obra o en el objeto, en la parte virtual de la obra o del objeto, sin que pueda designar un punto de vista privilegiado sobre los otros, un centro que sería unificador de los otros centros. (Deleuze, 2002, p. 315)

La inmaterialidad de lo virtual tiene su soporte material en los procesos digitalizados de las nuevas tecnologías: las computadoras, desde ahí se hace posible el establecimiento de la interacción del sujeto-objeto que se detona en esta realidad alternativa porque se altera, distorsiona y crean otras formas de percibir las realidades alternativas. La virtualidad es una imagen o espacio inmersivo que potencia formas de realidad nunca antes vividas o pensadas. La virtualidad provee experiencias reales que dislocan la continuidad del tiempo, la cronologías de los procesos continuos, asume la multilinealidad de procesos perceptuales que siempre están reconfigurándose en la actualización y virtualización de la propia experiencia. De esta manera, el tiempo y espacio pierden significado en su construcción tangible para potenciar el desbordamiento de sentido dada la asignificación del espacio y tiempo sin referentes concretos o tangibles.

La potencia de la inmersión virtual siempre es actualizadora, por lo que el tiempo, el espacio, la obra o $S E R$ no pueden nunca volver a ser los mismos. "Pero ese tiempo virtual determina un tiempo de diferenciación ${ }^{3}$ o más bien de ritmos, de tiempos diversos de actualización que corresponde a las relaciones y a las singularidades de la estructura, y que miden por su cuenta el pasaje de lo virtual a lo actual" (Deleuze, 2002 , p. 317). Lo virtual es un mundo potencial, un mundo latente que crea otras realidades. Lo virtual es el reino de lo que ya está constituido en tanto posibilidad de existencia. Desde el punto de vista tecnológico es un modo de creación de realidad, es una forma de vida creada a partir de la materialidad de los medios tecnológicos digitales y de la inmaterialidad de la virtualidad y la interacción de los sujetos. Lo actual y virtual en Deleuze no escinden al SER. Su filosofía propone lo uno y lo múltiple como una misma voz para múltiples voces, un solo y mismo océano para todas las gotas, un solo clamor del ser para todos los entes. 
A partir de las ideas de Deleuze, Rajchman (2004) dice que no debe confundirse la multiplicidad con nociones tradicionales de lo numeroso. No se trata de hacer diferentes combinaciones o diferencias sino de hacer un todo como lo uno y lo múltiple. Se trata de un todo que recupera múltiples singularidades: "Podríamos decir que una singularidad es lo que se incorpora a una serie, y una serie, a diferencias de un conjunto o un todo orgánico que es lo que está compuesto de singularidades" (Rajchman, 2004, p. 60). La multplicidad es una univocidad de singularidades. Lo unívoco de ser es el correlato de la inmanencia en el que se concibe al ser como Uno-Todo.

Siguiendo a Badiou (1992), lo virtual en el sentido filosófico:

Tiene su fundamento en el potencial que siempre se actualiza en lo múltiple. Lo virtual está no constituido en lo posible -esta es una idea a la que Deleuze le pone especial cuidado- no hay que confundir lo virtual con la posibilidad porque el concepto de virtual es un continente de la totalidad del Ser, de manera que lo virtual no es la posibilidad de que algo sea, lo virtual es ya la posibilidad de existencia. Esto significa que: puede existir, solo le falta la existencia. (p. 72)

Lo virtual no se antepone a lo real porque es otra forma de construcción de la realidad que se hace posible porque el ciberespacio es su medio, el espacio desterritorializado en que fluyen miles y millones de construcciones que edifican un nuevo espacio y una nueva realidad.

Lo virtual, por el contrario, no se opone a lo real, posee una plena realidad por sí mismo. Su proceso es la actualización. Se cometería un error si se ve en esto tan sólo una disputa verbal: se trata de la existencia misma. (Deleuze, 2002, p. 318)

Como se mencionó anteriormente, lo virtual en tanto forma de realidad desata nuevas formas de interacción social, perceptual o sensible nunca antes pensadas o conocidas, crea sujetos nómadas que circulan por las rutas múltiples que se despliegan como un devenir abierto y sin mapa que clausure su circulación. 
La materialidad e inmaterialidad en el arte digital...

La virtualización no se contenta con acelerar los procesos ya conocidos, ni con poner entre paréntesis, incluso con aniquilar, el tiempo o el espacio, como pretende Paul Virilio, sino que inventa, con el consumo y el riesgo, velocidades cualitativamente nuevas y espacios-tiempos mutuales. (Lévy, 1999, p. 24)

De esta manera, por un lado, lo material y físico son modos tangibles o registros fehacientes de cambios y transformaciones de condiciones materiales y estructurales. Por otro lado, lo inmaterial es el modo en el que se asume todo lo intangible de la obra: conductas, percepciones o formas de existencia que operan en el mundo de la obra de arte virtual de lo que existe como potencia de existencia sin que por ello pueda aún tener un sustrato material. Ambas formas de existencia se presentan en los objetos y productos del arte digital de modo inmanente.

\section{De las obras y la virtualidad}

Lo virtual en el arte no separa la materia de la sustancia, en términos inmanentes la materia contiene a la sustancia y la sustancia yace en la materia. Lo virtual en el arte, parece, crear una falsa ilusión de separación entre el soporte material de la obra y la sustancia sensible e inmaterial de la obra. Tal separación es ficticia porque el arte mismo, expresado en cualquier plataforma, soporte o dispositivo digital siempre asiste a una poética en que la forma y la idea sensible poseen ya una composición inmanente. Los efectos de la virtualidad de las obras artísticas se hacen operativos por medio de la interacción, porque logran establecer relaciones complejas entre el sujeto y el objeto virtual configurando así nuevas atmósferas y posibilidades de desplegarse en modos diversos de ser.

Siguiendo con lo anterior, lo virtual existe en la medida en la que el sujeto se adentra en los mundos virtuales, de manera que no se trata de alucinaciones digitalizadas, simulaciones, ilusiones sino de realidades vivibles, de modos de morar el mundo, de crear y configurar la imaginación que explaya siempre mundos nuevos, reales y alternativos como un seres nómadas que se despliegan en sus modos diversos de ser: actual-virtual. Así, la interacción modifica la percepción de la realidad virtual porque conecta los sentidos para reconectarlos de otro modo. Modificando lo perceptual, se privilegian las multisensorialidades. 
Los sujetos se conectan con los medios y es precisamente en esa conexión que se detona una compleja interacción de sentidos como nunca antes se habían conectado el espectador y el objeto virtual. Asistimos a una cultura que interconecta funciones neuroculturales en nuevas manifestaciones artísticas. "Nos enseñan cómo adaptarnos a las nuevas síntesis sensoriales, a las nuevas velocidades y percepciones" (Kerckhove, 1999, p. 56).

El concepto de virtualidad y la interación que provoca, trae de suyo, la modificación de procesos perceptuales, nuevas síntesis sensoriales en los cuerpos que se extienden por los estímulos de los sensores electrónicos, visuales, modificando los procesos sinestésicos y quinestésicos de los sujetos. Los productos de este arte se crean bajo la égida de las nuevas relaciones interactivas que propicia la realidad virtual.

En pocas palabras, en la RV (Realidad Virtual) desaparece la figura y la función del narrador, tanto como desaparecen las del público unificado. Y con ello se replantea brutalmente una discrepancia entre sensorialidad y narratividad, entre mímesis y diégesis, entre percepción y estructura. Como se replantean, no menos agudamente, la función y las tareas del espectador en relación con el espectáculo y con la fabulación representada. (Gubern, 2000, p. 209)

Asimismo, el cuerpo es el gran instrumento de la virtualidad, es el protagonista sensible que activa y hace significativa la obra, potencializando el despliegue del ser que mora nomádicamente como muchos modos y experiencias distintas. Lo virtual no es la pura inmaterial, es material e inmaterial a la vez. Si asumimos la realidad virtual:

(...) La RV no elimina la realidad o irrealidad como tales, sino que lo que erradica es la dicotomía, la separación, el límite que existía entre ellas. Con la irrupción de la RV aparecen formas híbridas entre lo que constituye la realidad y lo que constituye a lo no real o a lo virtual, porque entre lo real-irreal, entre lo que constituye la irrealidad y lo que constituye a lo no real o a lo virtual, porque ella misma, es decir, la Realidad Virtual, no está configurada por una mezcolanza de ambos espacios. En la RV las personas llevan a cabo acciones, desarrollan experiencias, entablan relaciones, interaccionan, constituyen y reconstituyen su identidad. (Tirado y Doménech, 2006, p. 8) 
La materialidad e inmaterialidad en el arte digital...

En otras palabras, no hay una escisión del ser en la experiencia de la virtualidad sino seres que se despliegan por sus diversos y múltiples modos de ser. El ser de despliega en mundos virtuales en los que se puede vivir, en donde se despliegan todo tipo de experiencias potenciales que se hacen virtuales. Se trata de otras formas de pensar, de vivir, mirar y percibir el mundo.

Desde el referente deleuziano, lo virtual no es una simple simulación que se mire desde la tecnología, sino una imagen de pensamiento siempre relacionada con la existencia de lo real, porque lo virtual mismo es ya real. Su potencia de existencia que deviene en realidad. Lo virtual una imagen de pensamiento potencializadora, actualizadora y realizadora de lo real. Lo virtual es fundamento para lo actual y lo virtual, como Ser de la virtualidad que lo actualiza: "Pero lo virtual es también fundamento de sí, porque es el ser de las virtualidades, en la exacta medida que las diferencia o problematiza" (Badiou, 1997, p. 75). En otras palabras, lo virtual comprendido como una multiplicidad de realidades que se actualizan desde sí. Lo virtual es un mundo potencial, un mundo latente que crea otras realidades, el reino de lo que ya está constituido en tanto posibilidad de existencia. "Virtual es un modo de ser, es un proceso de transformación de un modo de ser a otro modo de ser" (Lévy, 1999, p. 14).

Ahora bien, la inmaterialidad no es una desmaterialización, sino una transformación del estado de la materia que se hace intangible, virtual y posibilitada por la interactividad. Filosóficamente llamamos inmaterial a una entidad desprovista de materia. "Por lo común, se estima que una entidad inmaterial sólo (sic) es aprehensible por medio de actos cognoscitivos de índole racional, intelectual, etc. De esta manera, lo inmaterial puede ser descrito de muy diversas maneras" (Ferrater, 1965, p. 962).

En lo material se hallan los soportes físicos, la electricidad, el internet, el hardware, el software, las aplicaciones, los lenguajes de programación (las computadoras son algunos, de los artefactos tecnológicos que sirven a los artistas para crear obras interactivas complejas). Su propia configuración es material pero también inmaterial. 
No hay tiempo cronológico ni espacio físico, estas dimensionalidades dentro de la red ya no tienen principio y fin, por ejemplo, las nociones de tiempo y espacio desde los referentes sociales y en la Sociedad Red se hacen atemporales y desterritorializados. Hablamos de territorios intangibles, espacios en los que el hombre habita, entra y sale cuando quiere, lugares y tiempos desterritorializados en los que el hombre viaja dentro de un torrente de luz casi ilegible, inasible y, sin embargo, es lugar vivible. Los lugares físicos y los tiempos cronológicos se transfiguran, mutan, se reconstituyen ofreciendo nuevas posibilidades en las que circula la información a una velocidad vertiginosa difícil de asir.

No puede negarse que el arte digital posee un carácter material y uno inmaterial que a menudo son separados y escindidos, pero lo que no se puede afirmar es que estas dimensiones no existen de modo fragmentado o superior una de otra. Pensar esto como una univocidad igual a inmanencia es porque ya Deleuze piensa que el ser no estaría definido por nada previo o superior a él, porque este se trata de un complejo entramado que opera como un bucle sin fin desplegando siempre potencias actualizadoras del ser, con las que devienen nuevas formas en las cuales se construye la realidad a partir de la virtualidad. Lo actual virtual en tanto categorías inmanentes no separan el despliegue de la obra virtual ni de sujeto (interactor que asiste a su goce estético) sino que potencian su despliegue, actualizándolo y virtualizandolo para nunca volver a ser el mismo, siempre diferente, siempre cambiante. De tal modo ni la obra ni el sujeto vuelven a ser los mismos.

Nunca atribuimos toda la belleza de la obra virtual a lo que le es propio. Una parte importante de dicha belleza proviene de otro lugar, por ejemplo, de nosotros mismos. La obra es bella si vive de verdad y sólo (sic) vive de verdad cuando la vivificamos. Su vida es también la nuestra. Del encuentro surge la verdadera belleza de la obra, la que nos conmueve porque nos invita a reunirnos con ella. (Quéau, 1995, p. 133)

El espectador de este arte incorpora toda su corporalidad como un medio y medida de toda experimentación. Procesa las sensaciones inéditas, novedosas, extrañas e inesperadas que esta nueva obra le provee. La experiencia ocurre continuamente porque la obra es también un ser sintiente, una obra viva y activa. 
La materialidad e inmaterialidad en el arte digital...

La experiencia es un proceso vital, continuo e infinito que nunca termina de cerrarse, es un proceso al que el espectador está siempre dispuesto a entrar y moldear su mundo a través de su cuerpo a través de la inmanencia de lo material e inmaterial.

Los soportes digitales sobre los que se crean las obras digitales tienen efectos y consecuencias en los comportamientos de los espectadores y, por otro lado, los efectos de los espectadores no son solo una mera reacción a la apreciación de las obras de artes digital. Las emociones, sensaciones, los sueños, los juicios críticos, el pensamiento, la interacción, las ideas generadas por los artistas y por los espectadores son referentes inmateriales que tienen un claro soporte en la materialidad de las construcciones tangibles por lo que son producidos.

Osmose de Charlotte Davies (1995) desafía los enfoques convencionales de realidad virtual y nos muestra que la inmersión del usuario o espectador no es una simulación sino la construcción de realidades. La estética visual de Osmose es semi-representacional/semi-abstracto y translúcida, que consiste en texturas semitransparentes y partículas que fluyen. Existen relaciones entre figura y fondo las cuales son espacialmente ambiguas y las transiciones entre los mundos son sutiles y lentas.

(...) Desde el momento que una persona entra en el ciberespacio con un casco visualizador, deja de ser espectador pasivo para convertirse en un espectador-actor en el ámbito de los self-media. Puede que este operador, ya en el ciberespacio, decida entrar por una puerta a su derecha y avanzar por aquel itinerario. Pero, otro operador que llegue con él o tras él, en uso de su autonomía hipertextual, posiblemente optará por la puerta de la izquierda, y ambos tendrán, en consecuencia, vivencias, y seguramente sorpresas, muy distintas. El imaginario que es propio de los públicos tradicionales que comparten el mismo espectáculo, en el cine o la televisión, queda así dinamitado por la pluralidad de acciones y de vivencias. (Gubern, 2000, p. 208)

Los ambientes representados por la virtualidad pueden evocar cualquier lugar o sentimiento, en tanto que son los propios espectadores quienes dan vida activa a la obra desde sus propias significaciones. 
En Osmose, la obra virtual de Char Davies, los sonidos son espacialmente multidimensionales y fueron concebidos para responder a los cambios de dirección, velocidad o inmersiones, así como a los estímulos de la voz de los espectadores. Osmose es proyecto de realidad virtual (1995). Una instalación de entorno virtual interactiva de inmersión con ambientes y sonidos 3D (Tres dimensiones). Una pantalla montada en la cabeza y el movimiento de seguimiento en tiempo real basados en la respiración y el equilibrio. Osmose es un espacio para explorar la interacción perceptual entre el yo del espectador y un mundo envolvente, onírico e inmersivo, es decir, un lugar desterritorializado que potencializa el conocimiento sensible del propio espectador.

Grau (2003) piensa que la obra "Osmose" de Charlote Davies es una de las primeras obras virtuales que entrecruza muchas posibilidades estéticas, fenomenológicas y de percepción visual proponiendo a su vez una experiencia individual única. Grau describe Osmose como sigue:

La inmersión en Osmose comienza con la colocación del chaleco de la pantalla y el movimiento de seguimiento montado en la cabeza. El primer espacio virtual encontrado es una cuadrícula cartesiana tridimensional que funciona como un espacio de orientación. Con las primeras respiraciones del immersant, la red da paso a un claro en un bosque. [...] Hay una docena de espacios mundiales en Osmose, la mayoría basados en aspectos metafóricos de la naturaleza. Estos incluyen: Compensación, Bosque, Árbol, Hoja, Nube, Estanque, Subterránea, Tierra, y Abismos. También hay un sustrato, código, que contiene gran parte del software real que se utiliza para crear la obra, y un superestrato, texto, un espacio que consiste en citas de la artista y fragmentos de textos relevantes sobre la tecnología, el cuerpo y la naturaleza. Código y texto funcionan como paréntesis conceptuales en torno a los mundos dentro. [...] La interfaz de usuario se basa en la inmersión de todo el cuerpo en grado esférica, el espacio envolvente, a través del uso de una pantalla montada en la cabeza. Técnicas de interfaz en contraste con base manualmente como joysticks y trackballs. Osmose incorpora los procesos intuitivos de la respiración y el equilibrio como el principal medio de navegación dentro del mundo virtual. Por la inhalación de la inmersión es capaz de flotar hacia arriba, por la exhalación, para caer, y por la sutileza alterar el centro del cuerpo de equilibrio, para cambiar de dirección, un método inspirado por la práctica de buceo de control de flotabilidad. (Grau, 2003, p. 194) 
La materialidad e inmaterialidad en el arte digital...

Para concluir, es preciso dejar claro que toda la producción artística digital está atravesada por procesos de creación científica, tecnológica, y socioculturales cada vez más complejos. La obra de arte digital no puede pensarse fuera de estos ambientes y saberes porque más que nunca los artistas revelan su formación pluridisciplinaria con la que abordan problemas artísticos desde la perspectiva transdisciplinar, al no conformarse con la posesión de un solo o único conocimiento, sino ir y venir en campos transversales de investigación que los vincule en todo momento con una producción compleja y rica de las obras de arte. Tal parece que los purismos académicos o las trincheras cerradas de las disciplinas han quedado atrás y se da paso a la creación de obras complejas y de imágenes de síntesis. Tal reconfiguración del espacio de flujos o el ciberespacio hace que el espectador se mueva interactivamente en lo virtual de las obras de arte que le rodean. En el desarrollo de la sociedad global el concepto de la virtualidad implica nuevas formas de organización cultural y social de las prácticas del arte. De modo que, la virtualidad pone en relieve la parte inmaterial que da sentido a las prácticas del arte, no solo se digitalizan, sino que se configuran mediante circuitos electrónicos y procesos tecnológicos y científicos complejos. La experiencia artística que ofrece el arte digital no puede ser reducida a la materialidad, en tanto que es pura inmaterialidad, porque la configuración del espacio de flujos, el ciberespacio, la virtualidad e interacción que la caracteriza ha modificado los procesos de creación artística y la participación activa de los espectadores. 


\section{Notas}

1 "El empleo de la razón en el estudio racional de la Naturaleza es o físico o hiperfísico o, por mejor decirlo, o inmanente o trascendente. El primero se ocupa del conocimiento de la Naturaleza en cuanto puede ser aplicado a la experiencia (in concreto); el segundo, de aquella conexión de los objetos de la experiencia que trasciende toda experiencia. Como en otros aspectos de la filosofía kantiana, aquí también los idealistas postkantianos (especialmente Fichte y Schelling) proyectaron los significados de los principios a los "fundamentos de lo real". Así, por ejemplo, en Fichte la actividad del Yo es puramente inmanente, pero no porque se confine dentro de los límites de la experiencia posible, sino porque engendra el campo mismo de la experiencia" (Ferrater, 1965, p. 961).

2 El plano de inmanencia: "Los conceptos filosóficos son todos fragmentarios que no ajustan los unos con los otros, puesto que sus bordes no coinciden. Son más productos de dados lanzados por azar que piezas de un rompecabezas. Y sin embargo resuenan, y la filosofía que los crea presenta siempre un Todo poderoso, no fragmentado, incluso cuando permanece abierta: Uno-Todo ilimitado, Omnitodo, que los incluye a todos en un único y mismo plano. Es una mesa, una planicie, una sección. Es un plano de consistencia o, más exactamente, el plano de inmanencia de los conceptos, el planómeno". [...] "La filosofía es un constructivismo, y el constructivismo tiene dos aspectos complementarios que difieren en sus características: crear conceptos y establecer un plano" (Deleuze y Guattari, 1993, p. 39). [...] "El plano de inmanencia no es un concepto pensado ni pensable, sino la imagen del pensamiento, la imagen que se da a sí mismo de lo que significa pensar" (Deleuze y Guattari, 1993, p. 41). "Pero, pese a ser cierto que el plano de inmanencia es siempre único, puesto que es en sí mismo variación pura, tanto más tendremos que explicar por qué hay planos de inmanencia variados, diferenciados, que se suceden o rivalizan en la historia, precisamente según los movimientos infinitos conservados, seleccionados" (Deleuze y Guattari, 1993, p. 43). [...] "Evidentemente el plano no consiste en un programa, un propósito, un objetivo o un medio; se trata de un plano de inmanencia que constituye el suelo absoluto de la filosofía, su Tierra o su desterritorialización, su fundación, sobre los que crea sus conceptos" (Deleuze y Guattari, 1993, p. 45). [...] "El plano de inmanencia es como una sección del caos, y actúa como un tamiz. El caos, en efecto, se 
La materialidad e inmaterialidad en el arte digital...

caracteriza menos por la ausencia de determinaciones que por la velocidad infinita a la que éstas ( sic) se esbozan y se desvanecen [...] El caos caotiza, y deshace en lo infinito toda consistencia. El problema de la filosofía consiste en adquirir una consistencia sin perder lo infinito en el que el pensamiento se sumerge (el caos en este sentido posee una existencia tanto mental como física). Dar consistencia sin perder nada de lo infinito es muy diferente del problema de la ciencia, que trata de dar unas referencias al caos a condición de renunciar a los movimientos y a las velocidades infinitas y de efectuar primero una limitación de velocidad" [...] (Deleuze y Guattari, 1993, pp. 46-47). [...] "Lo que no puede ser pensado y no obstante debe ser pensado fue pensado una vez, como Cristo, que se encarnó una vez, para mostrar esta vez la posibilidad de lo imposible. Por ello Spinoza es el Cristo de los filósofos, y los filósofos más grandes no son más que apóstoles, que se alejan o acercan a este misterio. Spinoza, el devenir-filósofo infinito. Mostró, estableció, pensó el plano de inmanencia “mejor", es decir el más puro, el que no se entrega a lo transcendente ni vuelve a conferir transcendencia, el que inspira menos ilusiones, menos malos sentimientos y percepciones erróneas" (Deleuze y Guattari, 1993, p. 62).

${ }^{3}$ [differentiation]. 


\section{Referencias}

Alsina, P. (2007). Arte, Ciencia y Tecnología. Barcelona, España: Editorial UOC.

Alsina, P. y San Cornelio, G. (2010). On Flows, places and spaces: towards a framework for locative media artworks. En Heinzel, T. (2010). Art, Space and Technology in the Digital Age. Bucharest: Collection "Spatii Imaginate". Paideia.

Alsina, P. y San Cornelio, G. (2013). Breve genealogía de las prácticas artísticas vinculadas a la ciencia y a la tecnología. Barcelona, España: Editorial UOC.

Badiou, A. (1997). El clamor del ser. Buenos Aires, Argentina: Editorial Manantial.

Castells, M. (1996). La era de la información: economía, sociedad y cultura. Madrid, España: Alianza editorial.

Deleuze, G. y Guattari, F. (1993). ¿Qué es la filosofía? Barcelona, España: Anagrama.

Deleuze, G. (1996). Spinoza y el problema de la expresión. Barcelona, España: Atajos, Muchnik editores.

Deleuze, G. (2002). Diferencia y repetición. Buenos Aires, Argentina: Amorrortú editores.

Ferrater, J. (1965). Diccionario de Filosofía. Tomo 1. Buenos Aires: Sudamericana.

Gibson, W. (2001). Neuromante. Barcelona, España: Minotauro.

Grau, O. (2003). Virtual Art: From llusion to inmmersion. Massachusetts, Estados Unidos: MIT Press. 
La materialidad e inmaterialidad en el arte digital...

Gubern, R. (2000). El eros electrónico. Madrid, España: Taurus.

Kerckhove, D. (1999). Inteligencias en conexión: Hacia una sociedad de la Web. Barcelona, España: Gedisa.

Lefebvre, H. (1974). La producción del espacio. Papers: de Revista de sociología, 3, 219 -229. Recuperado de https://papers.uab.cat/article/view/v3-lefebvre/ pdf-es

Lévy, P. (1999). ¿Qué es lo virtual?. Barcelona, España: Paidós.

Lévy, P. (2007). Cibercultura: la cultura de la sociedad digital. México: Antropos y UAM Iztapalapa.

Quéau, P. (1995). Lo virtual: virtudes y vértigos. Barcelona, España: Paidós Ibérica.

Rajchman, J. (2004). Deleuze: un mapa. Buenos Aires, Argentina: Nueva Visión.

Silbermann, A. (1971). Introducción, situación y vocación de la sociología del arte. Sociología del Arte. Buenos Aires, Argentina: Nueva Visión.

Tirado, F. y Doménech, M. (2006). Lo social y lo virtual: nuevas formas de control y transformación social. Barcelona, España: UOC. 